\title{
PERUBAHAN SISTEM KONTROL DARI PLC KE DCS PADA GRUP BAG FILTER 563-BF1
}

\author{
Jefri Gunawan ${ }^{1}$, Fatahula ${ }^{2}$, Juhartono ${ }^{3}$ \\ ${ }^{1}$ Program Studi Teknik Mesin, Jurusan Teknik Mesin, Politeknik Negeri Jakarta, \\ ${ }^{2}$ Jurusan Teknik Elektro, Politeknik Negeri Jakarta, \\ Jl. Prof. G. A. Siwabessy, Kampus UI, Depok, 16425 \\ ${ }^{3}$ Electrical Engineer, Maintenance Department, PT Solusi Bangun Indonesia Tbk Pabrik Cilacap, \\ Jl. Ir. H. Juanda, Padaramai, Karangtalun, Cilacap Utara, Cilacap, 53224 \\ e-mail: ${ }^{1}$ jefri.eve12lafargeholcim@gmail.com, ${ }^{2}$ fatahula@gmail.com, \\ 3juhartono.sbi@semenindonesia.com
}

\begin{abstract}
Bag filter is an equipment in cement industries that used for handling dust from material or separate fines dust with air to make the area is not dusty and it is not make accumulation material. Bag filter (563-BF1) is used for handling dusty area at outlet ball mill in the cement making process. The working systems of bag filter group (563-BF1) is controlled by PLC (Programmable Logic Control). However, the PLC is obsolete so it takes a long time to handle when damage occurs and causes the risk of production loss reach $R p$ 1,301,801,760.00. In addition, communication systems between PLC with Central Control Room (CCR) that are less reliable cause communication to fail on April 2019 so that the equipment cannot be controlled. To overcome this, it is necessary to upgrade the PLC and communication system to the latest version or change it to DCS (Distributed Control System). Upgrading PLC requires huge costs with almost the same communication system reliability. While changing the control system to DCS is cheaper with better reliable system. So, we chose to change it to DCS. After that control system is changed to DCS on April 2019, the risk of production loss can be eliminated with saving cost in the amount of Rp 220,402,885.00 and after 3 month the communication failed is never occurs (it is more reliable).
\end{abstract}

Key words: PLC, DCS, Upgrade, Reliable

\begin{abstract}
ABSTRAK
Bag filter (BF) adalah suatu alat yang ada di pabrik semen yang berfungsi untuk sistem penanganan debu material atau pemisahan debu berukuran sangat halus dengan udara supaya area tidak berdebu dan tidak menimbulkan penumpukan material. Bag filter (563-BF1) digunakan untuk menangani debu pada keluaran ball mill pada proses pembuatan semen. Sistem kerja grup bag filter (563-BF1) dikontrol oleh PLC (Programmable Logic Control). Namun, PLC tersebut sudah obsolete sehingga butuh waktu penanganan yang lama ketika terjadi kerusakan dan berisiko menimbulkan kerugian produksi mencapai $R p$ 1,301,801,760.00. Selain itu, sistem komunikasi antara PLC dengan Central Control Room (CCR) yang kurang andal menyebabkan komunikasi gagal pada April 2019 sehingga peralatan tidak dapat di kontrol. Untuk mengatasinya, perlu dilakukan upgrade PLC dan sistem komunikasi ke versi terbaru atau mengubahnya ke DCS (Distributed Control System). Upgrade PLC memerlukan biaya besar dengan keandalan sistem komunikasi yang hampir sama. Sedangkan perubahan sistem kontrol ke DCS lebih murah dengan keandalan sistem yang lebih baik. Maka, kami memilih untuk mengubahnya ke DCS. Setelah sistem kontrol tersebut diubah ke DCS pada April 2019, risiko kerugian produksi dapat di hilangkan dengan menghemat biaya sebesar $\mathrm{Rp} 220,402,885.00$ dan setelah 3 bulan tidak pernah terjadi kegagalan komunikasi (lebih andal).
\end{abstract}

Kata kunci: PLC, DCS, Upgrade, Andal

\section{PENDAHULUAN}

Bag filter (BF) adalah suatu alat yang ada di pabrik semen yang berfungsi untuk sistem penanganan debu material atau pemisahan debu berukuran sangat halus dengan udara supaya area tidak berdebu dan juga tidak menimbulkan penumpukan material. Bag filter (563BF1) digunakan untuk menangani area 
berdebu pada keluaran ball mill pada proses pembuatan semen.

Bag filter finish mill 563-BF1 dalam melakukan pengendalian debu material, dibantu oleh peralatan lainnya seperti fan 563-FN1 untuk menghisap udara dan debu, damper 563-TV1 untuk mengatur bukaan pipa keluaran bag filter, screw conveyor 563-SC1 untuk mendistribusikan debu yang sudah dipisah, dan rotary feeder 563-RF1 untuk mengontrol aliran debu. [4, 5]

Keseluruhan proses pada peralatan tersebut menggunakan sistem kontrol berbasis PLC (Programmable Logic Control). Namun, PLC yang sekarang digunakan sudah tidak ada suku cadang dan dukungan pembuat sehingga tidak bisa melakukan penggantian suku cadang ketika PLC tersebut rusak [8]. Akibatnya akan terjadi kerugian produksi sebesar Rp 1,301,801,760.00 jika tidak segera ditangani.

Jika dilakukan penggantian PLC dengan seri baru akan membutuhkan biaya yang besar. Selain itu, sistem PLC yang kurang andal juga menyebabkan kegagalan komunikasi mencapai 2-3 kali dalam setahun. Pada tahun 2019 telah terjadi kegagalan komunikasi pada 10 April 2019 yang menyebabkan peralatan di lapangan tidak dapat di kontrol.

Atas rekomendasi dari Electrical Head PT Solusi Bangun Indonesia Tbk Pabrik Cilacap, sistem kontrol tersebut diganti dengan DCS (Distributed Control System) dengan harapan terhindar dari risiko kerugian produksi yang besar dan sistem kontrol menjadi lebih andal. Selain itu dapat menghemat biaya karena tidak perlu membeli PLC versi terbaru.

Tujuan dari penelitian ini adalah untuk menghilangkan risiko terjadinya kerugian produksi yang diakibatkan oleh kerusakan pada PLC grup bag filter 563-BF1 tanpa mengeluarkan biaya yang besar dan menyederhanakan sistem kontrol pada grup bag filter 563-
BF1 agar tidak terjadi kegagalan komunikasi lagi antara sistem kontrol bag filter 563-BF1 dengan CCR (Central Control Room).

\section{METODE PENELITIAN}

Berdasarkan Gambar 1, metode yang digunakan adalah pertama mengumpulkan informasi untuk menunjang proses perubahan sistem kontrol. Informasi tersebut antara lain yaitu dokumentasi kelistrikan dan instrumentasi dari grup bag filter 563BF1 yang terkait dengan daftar input output PLC, schematic drawing, layout panel, sequence drawing, dan wiring diagram sistem kontrol. Selain itu dibutuhkan informasi tentang DCS yang akan digunakan sebagai dasar penentuan komponen yang akan digunakan. [3,10]

Setelah mendapatkan informasi yang diperlukan, dilakukan pemilihan komponen DCS berdasarkan informasi daftar input output PLC yang digunakan dan tipe-tipe komponen yang sesuai dengan spesifikasi alat yang digunakan pada grup bag filter 563-BF1 dan sistem kontrol DCS yang akan digunakan. [9] Oleh karena itu, bisa ditentukan tipe dan jumlah komponen yang dibutuhkan dalam pelaksanaan proyek ini. Setelah dibuatkan daftar komponen dan biaya maka didapatkan perkiraan biaya yang akan dikeluarkan untuk proses pembelian komponen yang dibutuhkan dalam proyek. Jika biaya tersebut tidak disetujui maka kembali lagi ke proses penentuan daftar komponen dan biaya.

Setelah daftar komponen dan perkiraan biaya sudah disetujui maka dapat dilakukan diskusi tentang bagaimana tahapan-tahapan yang dilakukan ketika perencanaan yang dapat menunjang proses eksekusi. Pada tahapan ini dilakukan diskusi mengenai konsep penggambaran schematic dan layout drawing, penggambaran ulang tersebut 
disesuaikan dengan DCS yang akan digunakan. Setelah dilakukan diskusi maka diperoleh kesepakatan dan standar penggambaran yang sesuai dengan electrical wiring grup bag filter 563BF1. [2, 6]

Hasil dari diskusi tersebut kemudian di realisasikan pada tahapan eksekusi. Di dalam tahapan eksekusi dilakukan penggambaran schematic dan layout drawing, penyiapan dan pemasangan RIO (Remote Input Output) panel, koneksi antar komponen, migrasi sistem kontrol dan komisioning.

Schematic drawing yang dibuat tidak mengubah koneksi kabel dari terminal ke beban tetapi hanya mengubah koneksi kabel dari terminal I/O PLC menuju DCS, karena dilakukan daftar I/O yang baru dan dengan komponen baru dari DCS sehingga koneksi tersebut harus diubah.

Setelah proses eksekusi selesai, dilakukan evaluasi. Evaluasi tersebut antara lain melakukan tes sinyal pada opto coupler module card digital input dan output, DCS analog input module, dan DCS analog output module. Ketika ditemukan kesalahan pada tahap ini maka akan segera dievaluasi dan dibenahi kembali ke tahap diskusi sehingga kesalahan yang timbul dapat dihilangkan dan diharapkan tidak akan timbul kembali. [3,10]

\section{HASIL DAN PEMBAHASAN}

\section{Identifikasi Akar Masalah pada Grup Bag Filter 563-BF1}

Berdasarkan gambar 2, permasalahan utama pada grup bag filter 563-BF1 yaitu PLC yang digunakan sudah tidak ada suku cadang dan dukungan pembuat sehingga tidak dapat melakukan penggantian suku cadang ketika PLC tersebut rusak. Akibatnya, akan terjadi kerugian produksi yang besar karena jika tidak segera diatasi dapat menyebabkan finish mill berhenti beroperasi.
Selain menyebabkan terjadinya risiko kerugian besar, hal tersebut juga menyebabkan sistem komunikasi antara PLC dengan Central Control Room (CCR) menjadi tidak andal yang ditandai dengan terjadinya kegagalan komunikasi pada 10 April 2019 seperti tampak pada gambar 3. Ketika terjadi kegagalan komunikasi maka peralatan grup bag filter 563-BF1 yang berada di lapangan tidak dapat dikontrol. Hal tersebut membuat kondisi di lapangan menjadi tidak aman karena peralatan lepas kendali.

Jika PLC rusak secara tiba-tiba, karena sudah tidak memiliki suku cadang dan dukungan dari vendor maka membutuhkan waktu kurang lebih 3 hari untuk memperbaikinya. Hal tersebut menyebabkan finish mill berhenti beroperasi. Selama finish mill tidak beroperasi, ada biaya-biaya tetap yang harus dibayar meskipun seluruh peralatan tersebut tidak beroperasi sehingga menimbulkan kerugian. Sesuai dengan biaya produksi klinker dan semen per ton periode November 2018 Pabrik Cilacap pada tabel 1.

Maka total kerugian yang harus dibayar dari pembayaran biaya tetap sebesar =

Total biaya tetap produksi per ton semen $\times$ Kapasitas Produksi ton per jam $\times$ durasi stop $=\operatorname{Rp} 86,098.00$ per ton $\times$ 210 ton/jam $\times 72$ jam $=\mathrm{Rp}$ 1,301,801,760.00.

\section{Pemilihan Solusi Alternatif}

Berdasarkan akar masalah di atas maka ada 2 cara untuk mengatasi PLC yang sudah obsolete dan sistem tidak andal yaitu:

\section{Mengubah Sistem Kontrol ke DCS}

Biaya untuk mengubah sistem kontrol pada grup bag filter 563-BF1 ke DCS lebih murah dari pada melakukan upgrade PLC ke versi terbaru. Dengan DCS maka tidak memerlukan banyak komponen komunikasi agar peralatan di lapangan dapat di kendalikan melalui CCR sehingga sistem komunikasi menjadi lebih andal. Sesuai dengan 
standar sistem otomasidi PT Solusi Bangun Indonesia Tbk, untuk peralatan yang memiliki program yang sederhana termasuk ke dalam sistem kontrol utama yang dikontrol oleh DCS, dan dengan sistem redundancy pada DCS maka ketersediaan grup bag filter 563-BF1 selalu terjaga. [3,10]

\section{Upgrade PLC}

Upgrade PLC relatif lebih mudah dilakukan karena hanya mengganti komponen-komponen yang sudah obsolete dan memprogram ulang sesuai dengan program yang lama. Dengan begitu maka durasi pengerjaannya akan lebih cepat dibandingkan dengan mengubah sistem kontrol ke DCS.

Berdasarkan tabel 2, pemilihan solusi alternatif ditentukan berdasarkan prioritas kebutuhan konsumen yang dihitung menggunakan kalkulator AHP (Analytic Hierarchy Process) untuk menentukan bobot dari setiap kebutuhan.[1] Bobot tersebut dikalikan dengan penilaian pada masing-masing solusi alternatif dan di jumlahkan sehingga didapatkan skor dari masingmasing solusi alternatif. Dari hasil tersebut, didapat hasil kriteria pilihan yang sesuai dengan kebutuhan konsumen.

Jadi, setelah menilai menggunakan matriks penilaian konsep di atas sesuai dengan kriteria pilihan yang dibutuhkan oleh konsumen, proses perancangan alat pada penelitian ini menggunakan solusi alternatif 1 yaitu mengubah sistem kontrol pada grup bag filter 563-BF1 ke DCS.

\section{Analisis Perbandingan Biaya Komponen}

Berdasarkan tabel 3 dan tabel 4 yaitu tabel daftar komponen yang diperlukan untuk upgrade PLC dan migrasi sistem kontrol ke DCS, maka dapat disimpulkan bahwa untuk mengubah sistem kontrol grup bag filter 563-BF1 ke DCS lebih murah daripada melakukan upgrade PLC. Biaya yang dapat dihemat dengan mengubah sistem kontrol ke DCS yaitu Rp 309,636,965.00 - Rp 89,262,880.00 = Rp 220,402,885.00.

\section{Analisis Penyederhanaan Sistem Kontrol}

Berdasarkan gambar 4, agar peralatan di lapangan yang menggunakan PLC dapat di kontrol oleh CCR (Central Control Room) memerlukan banyak komponen sistem kontrol dan sistem komunikasi. Jumlah titik kemungkinan terjadinya gangguan dari PLC ke DCS mencapai 11 titik yaitu pada profibus, F/O profibus converter\&repeater, fiber optic, F/O profibus converter\&repeater, profibus, PLC gateway, ethernet, PC gateway, ethernet, OPC, dan E Net Centum VP.

Sedangkan berdasarkan gambar 5 agar peralatan di lapangan dapat di kontrol oleh CCR memerlukan komponen sistem kontrol dan sistem komunikasi yang lebih sedikit. Jumlah titik kemungkinan terjadinya gangguan hanya satu yaitu pada RIO Bus, sehingga dengan mengubah sistem kontrol dari PLC ke DCS, sistem komunikasi akan lebih andal daripada melakukan upgrade PLC dengan perbandingan kemungkinan terjadinya gangguan yaitu $1: 11$. Selain itu secara topologi, DCS juga merupakan sistem kontrol utama, sedangkan PLC termasuk dalam sub kontrol sistem sehingga DCS lebih andal dan tidak pernah terjadi kegagalan komunikasi.

\section{Penentuan Komponen}

\section{Kebutuhan Fuse}

Beban terbesar pada rangkaian kontrol ini yaitu opto coupler dengan arus maksimal $5 \mathrm{~mA}$. Dalam satu rangkaian maksimal menerima beban 3 opto coupler sehingga beban arus yang di terima maksimal $15 \mathrm{~mA}$. Karena In $\leq \mathrm{I}$ fuse maka penulis memutuskan memakai fuse $0.5 \mathrm{~A}$.

\section{Kebutuhan Relay}

Kebutuhan relay untuk rangkaian ini hanya membutuhkan jenis relay dengan tegangan sumber 220 VAC. Maka 
penulis memilih jenis relay sesuai dengan ketersediaan stok yaitu relay OMRON MY4N dengan jenis Quadruple Pole Double Throw (QPDT) yang memiliki 14 terminal, termasuk 2 untuk koil.

\section{Kebutuhan Penghantar}

Berdasarkan tabel kemampuan hantar arus terus menerus pada standar PUIL 2000 maka luas penampang nominal yang di perbolehkan untuk dilewati arus nominal $15 \mathrm{~mA}$ yaitu lebih besar dari $0.5 \mathrm{~mm}^{2}$. Maka penulis memilih kabel NYAF $1 \mathrm{~mm}^{2}$ karena ketersediaan stok.

\section{Kebutuhan Terminal Blok}

Berdasarkan perhitungan luas penampang kabel, maka ukuran terminal kabel yang digunakan adalah jenis Phoenix Contact tipe UK $3 \mathrm{~N}$ dengan spesifikasi tegangan maksimal $600 \mathrm{~V}$ dan luas penampang kabel maksimal 2,5 $\mathrm{mm}^{2}$.

\section{Kebutuhan Wire Duct}

Penulis menggunakan wire duct dengan ukuran luas $44 \times 45 \mathrm{~mm}$ dengan keseluruhan luas penampang $1980 \mathrm{~mm}^{2}$. Ukuran ini dipilih karena ketersediaan stok yang ada dan mempertimbangkan luas spasi dari bagian dalam panel. Ukuran wire duct sekian dapat menampung kabel kontrol dengan diameter rata-rata $1 \mathrm{~mm}^{2}$ sebanyak 1980 kabel.

\section{Proses Eksekusi}

Untuk mengubah sistem kontrol grup bag filter 563-BF1 dari PLC ke DCS, kita perlu menyiapkan komponenkomponen RIO (Remote Input Output) Panel terlebih dahulu. Setelah semua komponen siap dan sudah terpasang maka dapat dilakukan koneksi antar komponen. Saat finish mill jalur satu sedang tidak beroperasi kita dapat melakukan migrasi sistem kontrol dengan cara memindahkan seluruh sinyal grup bag filter 563-BF1 dari terminal I/O PLC ke marshalling yang sudah disiapkan pada RIO Panel DCS.

Komponen-komponen yang harus disiapkan dan dipasang diberikan oleh gambar 6. Komponen-komponen tersebut antara lain marshalling, Opto PB32 Card DI dan DO, Digital Module Card ADM52C dan ADM12C, Analog Module Card AAM11 dan AAM51. Untuk koneksi dari marshalling ke Opto PB32 Card menggunakan hardwire sedangkan dari Opto PB32 Card ke module digital menggunakan kabel KS10. Untuk komponen RIO panel secara fisik dapat dilihat pada gambar 7 .

Marshalling berada di antara sinyal digital dari lapangan (DI dan DO) dengan Opto PB32 Card. Ini berfungsi untuk memudahkan proses pengecekan dan pengukuran saat troubleshooting [7]. Sedangkan sinyal analog langsung di hubungkan ke Analog Module Card AAM11 dan AAM51.

\section{KESIMPULAN}

Perubahan sistem kontrol dari PLC ke DCS pada April 2019 telah menghilangkan risiko terjadinya kerugian produksi sebesar Rp 1,301,801,760.00 yang diakibatkan oleh kerusakan pada PLC bag filter finish mill. Biaya yang dikeluarkan untuk mengubah sistem kontrol ke DCS lebih murah daripada melakukan upgrade PLC dengan selisih Rp 220,402,885.00. Setelah dilakukan penyederhanaan sistem kontrol, kegagalan komunikasi sudah tidak pernah terjadi selama 3 bulan setelah proses eksekusi.

UCAPAN TERIMAKASIH 
Penulis mengucapkan terima kasih kepada PT Solusi Bangun Indonesia Tbk atas dukungan finansialnya pada kegiatan ini. Penulis juga berterima kasih kepada Bapak Fatahula, S.T., M.Kom, dan Bapak Juhartono, S.T., M.M., atas bimbingannya yang bermanfaat serta kepada karyawan dan kontraktor PT. Solusi Bangun Indonesia Tbk Pabrik Cilacap atas kerja samanya di kegiatan ini.

\section{DAFTAR PUSTAKA}

[1] AHP Calculator, 2019. AHP calculator - AHP-OS.

[2] Badan Standardisasi Nasional. 2002. Persyaratan Umum Instalasi Listrik 2000 (PUIL 2000). Jakarta: Yayasan PUIL.

[3] Budi Susanto, Ardiansyah. Centum VP System Overview. Jakarta: PT. Yokogawa Indonesia

[4] De Luca, Arnaud. 2007. Bag Filter, Vol. 5, 101-117.
[5] EVE. Cement-Process Technology Manual 2nd Semester. Cilacap, PT Holcim Indonesia Tbk.

[6] Holcim Indonesia. 2014. Standard Design Criteria (StDC) Electrical Equipment and System.

[7] https://automationforum.co/, 2019. Panel Marshalling.

[8] https://www.rockwelautomation.co m/, 2019. Lifecycle Status Processor PLC.

[9] Pratama, Transavia. 2004.Otomasi Wiring Diagram Control System. Cilacap: PT Semen Cibinong Indonesia.

[10] Yokogawa. 2012. Centum VP Engineering Training Manual. Vigilant: Yokogawa Electric Corporation.

[11] Yunan, SM. 2006. Dasar Sistem Kontrol Berbasis PLC. Seminyakkuta.

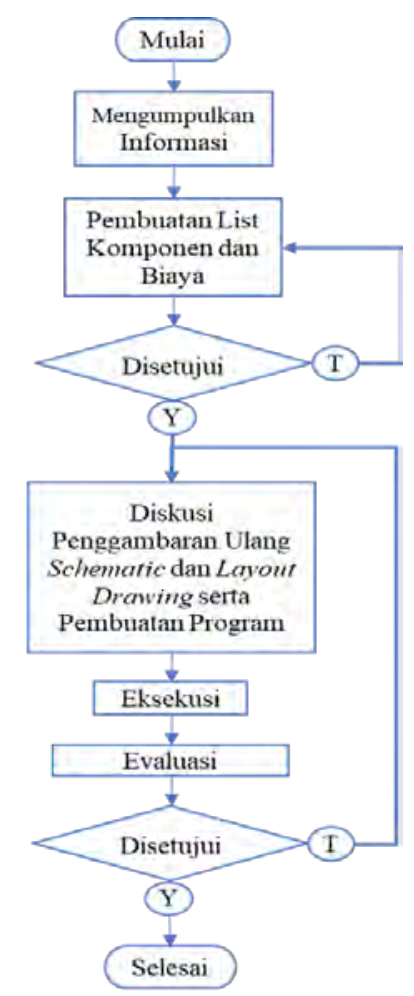

Catatan: $\mathrm{Y}=$ Ya: $\mathrm{T}=$ Tidak. 
Gambar 1. Diagram alir metode perubahan sistem kontrol

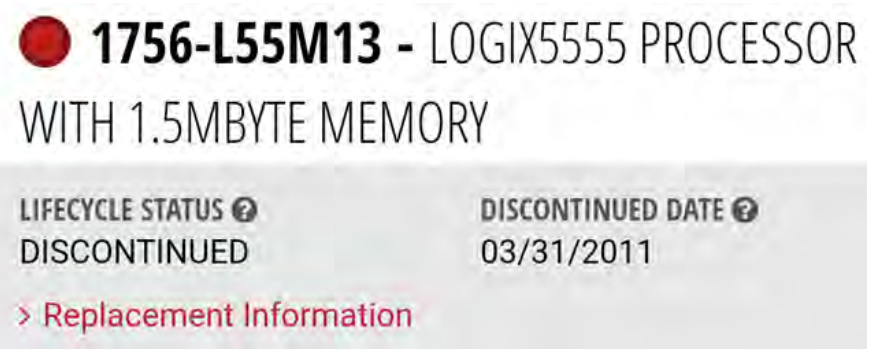

Gambar 2. Lifecycle status processor plc finish mill[8]

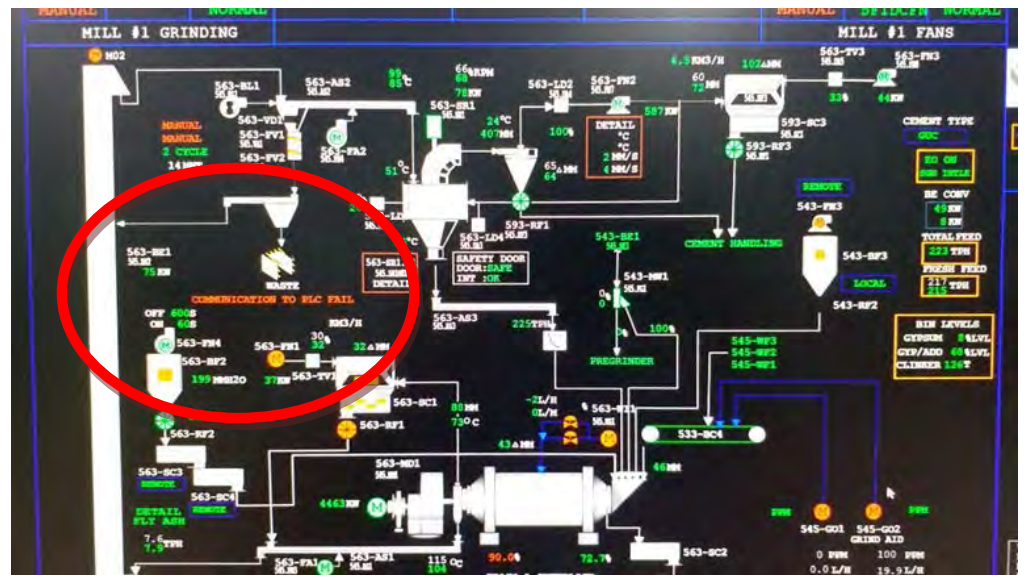

Gambar 3. Komunikasi PLC ke CCR gagal

Tabel 1. Biaya tetap per ton semen 


\begin{tabular}{|c|c|c|c|c|c|c|}
\hline \multirow{2}{*}{$\begin{array}{l}N \\
0\end{array}$} & \multirow{2}{*}{$\begin{array}{c}\text { CE Cost } \\
\text { Element } \\
\text { Description }\end{array}$} & $\begin{array}{c}\text { Total } \\
\text { Clinker }\end{array}$ & \multicolumn{2}{|c|}{ Cement Grinding } & \multirow{2}{*}{$\begin{array}{c}\text { Total } \\
\text { Raw Mat } \\
\text { Cost } \\
\text { directly } \\
\text { cons.in } \\
\text { cem } \\
\text { Cost per } \\
\text { Ton Cem } \\
\end{array}$} & \multirow{2}{*}{$\begin{array}{c}\text { Total } \\
\text { Production } \\
\text { Cost }\end{array}$} \\
\hline & & $\begin{array}{l}\text { Cost per } \\
\text { Ton Cem }\end{array}$ & Cost & $\begin{array}{l}\text { Cost per } \\
\text { Ton Cem }\end{array}$ & & \\
\hline 1 & $\begin{array}{l}\text { Electrical } \\
\text { Energy Fixed }\end{array}$ & - & - & - & - & - \\
\hline 2 & $\begin{array}{l}\text { Labor Expenses } \\
\text { Own }\end{array}$ & 23,390 & $15,583,409,267.00$ & $6,817.00$ & 2,205 & 32,412 \\
\hline 3 & $\begin{array}{l}\text { Labor Expenses } \\
\text { Subcontracted } \\
\text { Fixed }\end{array}$ & - & - & - & - & - \\
\hline 4 & $\begin{array}{l}\text { Labor Expenses } \\
\text { Maintenance } \\
\text { Own }\end{array}$ & 7,058 & $7,818,831,887.00$ & $3,420.00$ & 98 & 10,577 \\
\hline 5 & $\begin{array}{l}\text { Labor Expenses } \\
\text { Maintenance } \\
\text { Subcontracted } \\
\text { Fixed }\end{array}$ & - & - & - & - & - \\
\hline 6 & $\begin{array}{l}\text { Other Personel } \\
\text { Expenses }\end{array}$ & 2,914 & $2,396,505,081.00$ & $1,048.00$ & 216 & 4,178 \\
\hline 7 & $\begin{array}{l}\text { Third Party } \\
\text { Services }\end{array}$ & 10,403 & $6,491,284,765.00$ & $2,840.00$ & 760 & 14,003 \\
\hline 8 & $\begin{array}{l}\text { Third Party } \\
\text { Services } \\
\text { Maintenance }\end{array}$ & 4,244 & $1,856,765,623.00$ & 812.00 & 272 & 5,328 \\
\hline 9 & $\begin{array}{l}\text { Mantenance } \\
\text { Material }\end{array}$ & 10,171 & $5,471,769,843.00$ & $2,394.00$ & 817 & 13,381 \\
\hline 10 & $\begin{array}{l}\text { Other Cost } \\
\text { Center Expenses }\end{array}$ & 4,587 & $7,432,096,679.00$ & $3,251.00$ & 83 & 7,922 \\
\hline 11 & $\begin{array}{l}\text { By-Products and } \\
\text { Other Revenues }\end{array}$ & $(1,100.00)$ & $(1,378,046,822.00)$ & $(603.00)$ & $(1.00)$ & $(1,703.00)$ \\
\hline & $\begin{array}{l}\text { Total Fixed } \\
\text { Cash Cost }\end{array}$ & $61,667.00$ & $45,672,616,323.00$ & $19,979.00$ & $4,450.00$ & $86,098.00$ \\
\hline
\end{tabular}

Tabel 2. Matriks penilaian konsep

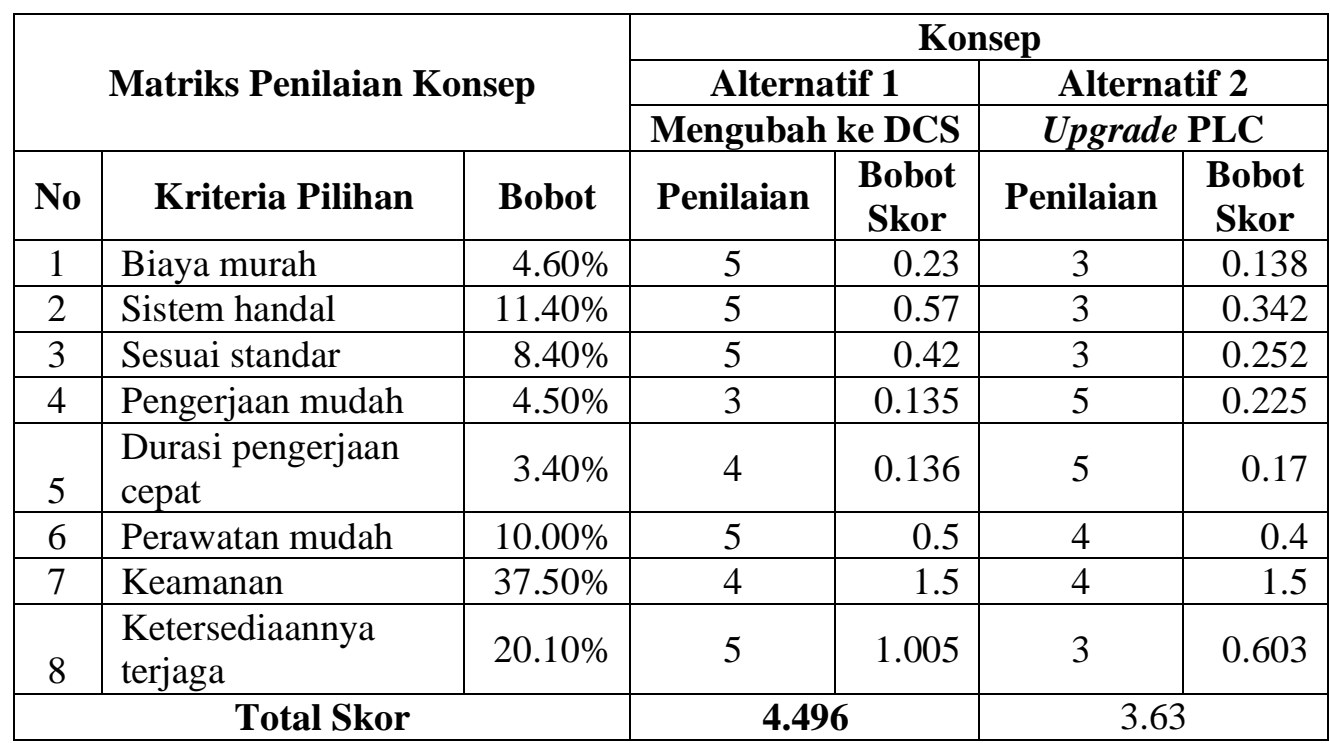


Tabel 3. Daftar biaya komponen upgrade PLC Allen Bradley Control Logic

\begin{tabular}{|c|c|c|c|c|c|}
\hline No & $\begin{array}{c}\text { Nama } \\
\text { Komponen }\end{array}$ & Harga (Rp) & Deskripsi & Est & Total (Rp) \\
\hline 1 & 1756-IM16I & $3,035,713.00$ & $\begin{array}{l}\text { Module;Digital;Input;1756- } \\
\text { IM16I;Allen B. }\end{array}$ & 1 & $3,035,713.00$ \\
\hline 2 & $\begin{array}{l}\text { 1756- } \\
\text { OA16I }\end{array}$ & $4,857,825.00$ & $\begin{array}{l}\text { Module;Digital;Output;1756- } \\
\text { OA16I;Allen B }\end{array}$ & 1 & $4,857,825.00$ \\
\hline 3 & $\begin{array}{l}\text { 1756- } \\
\text { ENBT/A }\end{array}$ & $11,730,600.00$ & $\begin{array}{l}\text { Module;Ethernet Comm;1756- } \\
\text { ENBT/A;Allen B. }\end{array}$ & 1 & $11,730,600.00$ \\
\hline 4 & 1756-A7 & $2,897,500.00$ & $\begin{array}{l}\text { Rack Chasis Slot;7 Slot;1756- } \\
\text { A7;Allen B. }\end{array}$ & 1 & $2,897,500.00$ \\
\hline 5 & $\begin{array}{l}1756- \\
\text { CNB/D } \\
1756\end{array}$ & $8,698,200.00$ & $\begin{array}{l}\text { Scanner;Remote;1756-CNB/D } \\
\text { 1756;Allen B. }\end{array}$ & 1 & $8,698,200.00$ \\
\hline 6 & 1756-A13 & 4,389,000.00 & $\begin{array}{l}\text { Rack;Main;13 Slot;1756- } \\
\text { A13;Allen B. }\end{array}$ & 1 & $4,389,000.00$ \\
\hline 7 & 1756-L55 & $35,186,812.00$ & $\begin{array}{l}\text { Module;CPU;Control } \\
\text { Logix;1756-L55;Allen }\end{array}$ & 1 & $35,186,812.00$ \\
\hline 8 & 1756-PA75 & $6,713,175.00$ & $\begin{array}{l}\text { Module;Power Supply;1756- } \\
\text { PA75;Allen B. }\end{array}$ & 1 & 6,713,175.00 \\
\hline 9 & 1756-BA2 & $570,000.00$ & $\begin{array}{l}\text { Battery;PLC;P/N 1756- } \\
\text { BA2;Allen Bradly }\end{array}$ & 1 & $570,000.00$ \\
\hline 10 & $\begin{array}{l}\text { 1756- } \\
\text { PA72/B }\end{array}$ & $7,500,000.00$ & $\begin{array}{l}\text { Module;Power } \\
\text { Supply;AC;1756-PA72/B;AB }\end{array}$ & 1 & $7,500,000.00$ \\
\hline 11 & $\begin{array}{l}1756- \\
\text { OA161 }\end{array}$ & $8,250,000.00$ & $\begin{array}{l}\text { Module;Dig.Output;P/N 1756- } \\
\text { OA161;AB }\end{array}$ & 1 & $8,250,000.00$ \\
\hline 12 & $\begin{array}{l}\text { 1756- } \\
\text { IM161 }\end{array}$ & $6,050,000.00$ & $\begin{array}{l}\text { Module;Dig.Input;P/N 1756- } \\
\text { IM161;AB }\end{array}$ & 1 & $6,050,000.00$ \\
\hline 13 & 1756-L71 & $26,500,000.00$ & $\begin{array}{l}\text { CPU;Controler;2MB;P/N } \\
\text { 1756-L71;AB }\end{array}$ & 1 & $26,500,000.00$ \\
\hline 14 & 1756-EN2T & $28,900,000.00$ & $\begin{array}{l}\text { Module;Ethernet;P/N 1756- } \\
\text { EN2T;AB }\end{array}$ & 1 & $28,900,000.00$ \\
\hline 15 & 1756-IF16 & $12,663,500.00$ & $\begin{array}{l}\text { Module;Analog Input;1756- } \\
\text { IF16;AB }\end{array}$ & 1 & $12,663,500.00$ \\
\hline 16 & $\begin{array}{l}1756- \\
\text { OF6C1 }\end{array}$ & $26,300,000.00$ & $\begin{array}{l}\text { Module;Analog Output;P/N } \\
\text { 1756-OF6C1;AB }\end{array}$ & 1 & $26,300,000.00$ \\
\hline 17 & $\begin{array}{l}\text { Control } \\
\text { Logix }\end{array}$ & $115,394,640.00$ & $\begin{array}{l}\text { Studio5000 Logix Designer; } \\
\text { 9324-RLD700NXENE }\end{array}$ & 1 & $115,394,640.00$ \\
\hline \multicolumn{5}{|c|}{ Biaya Total } & $309,636,965.00$ \\
\hline
\end{tabular}

Tabel 4. Daftar biaya komponen migrasi sistem kontrol ke DCS 
Jefri Gunawan, Fatahula dan Juhartono, Perubahan Sistem Kontrol...

\begin{tabular}{|c|c|c|c|c|c|}
\hline No & Nama & Harga (Rp) & Deskripsi & Est & Total (Rp) \\
\hline 1 & $\begin{array}{l}\text { G4PB32JY- } \\
\text { IN }\end{array}$ & $3,500,000.00$ & $\begin{array}{l}\text { Module;Card;Digital Input;P/N } \\
\text { G4PB32JY-IN;Opto } \\
\text { Coupler;Output } \\
\text { Assembly;MFG.Yokogawa;for } \\
\text { CC.402 }\end{array}$ & 1 & $3,500,000.00$ \\
\hline 2 & G4-IAC5A & $276,800.00$ & $\begin{array}{l}\text { Module;Card;Digital } \\
\text { Input;DCS;P/N G4- } \\
\text { IAC5A;Input } \\
\text { 240VAC;5VDC;Opto } \\
\text { Coupler;Input Unit;Opto } \\
\text { 22;MFG.Yokogawa }\end{array}$ & 10 & $2,768,000.00$ \\
\hline 3 & G4O AC5A & $502,820.00$ & $\begin{array}{l}\text { Module;Card;Digital } \\
\text { Output;P/N G4- } \\
\text { OAC5A;240VAC;3A;5V } \\
\text { Logix;Opto 22;MFG.Yokogawa }\end{array}$ & 4 & $2,011,280.00$ \\
\hline 4 & $\begin{array}{l}\text { G4PB32JY- } \\
\text { Out }\end{array}$ & $3,500,000.00$ & $\begin{array}{l}\text { Module;Card;Digital Input;P/N } \\
\text { G4PB32JY-Out;Opto } \\
\text { Coupler;Input } \\
\text { Assembly;MFG.Yokogawa }\end{array}$ & 1 & $3,500,000.00$ \\
\hline 5 & ADM12C & $14,900,000.00$ & $\begin{array}{l}\text { DCS Contact Input Module PN: } \\
\text { ADM12C; Yokogawa }\end{array}$ & 1 & $14,900,000.00$ \\
\hline 6 & ADM52C & $14,900,000.00$ & $\begin{array}{l}\text { DCS Contact Output Module } \\
\text { PN: ADM52C; Yokogawa }\end{array}$ & 1 & $14,900,000.00$ \\
\hline 7 & AAM11 & $7,800,000.00$ & $\begin{array}{l}\text { DCS Analog Input Module PN: } \\
\text { AAM11; Yokogawa }\end{array}$ & 3 & $23,400,000.00$ \\
\hline 8 & AAM51 & $7,270,000.00$ & $\begin{array}{l}\text { DCS Analog Output Module } \\
\text { PN: AAM51; Yokogawa }\end{array}$ & 1 & $7,270,000.00$ \\
\hline 9 & Kabel KS10 & $4,460,000.00$ & $\begin{array}{l}\text { Cable to Connect Digital } \\
\text { Module to PB32 card }\end{array}$ & 2 & $8,920,000.00$ \\
\hline 10 & $\begin{array}{l}\text { Kabel } \\
\text { Kontrol }\end{array}$ & $18,000.00$ & $\begin{array}{l}\text { Cable;NYAF;11mm } \\
\text { SQ;Federal;Black }\end{array}$ & 33 & $594,000.00$ \\
\hline 11 & $\begin{array}{c}\text { Kabel } \\
\text { Kontrol }\end{array}$ & $18,000.00$ & $\begin{array}{l}\text { Cable;NYAF;11mm } \\
\text { SQ;Federal;Red }\end{array}$ & 33 & $594,000.00$ \\
\hline 12 & $\begin{array}{l}\text { Kabel } \\
\text { Kontrol }\end{array}$ & $18,000.00$ & $\begin{array}{l}\text { Cable;NYAF;11mm } \\
\text { SQ;Federal;Yellow }\end{array}$ & 23 & $414,000.00$ \\
\hline 13 & $\begin{array}{l}\text { Kabel } \\
\text { Kontrol }\end{array}$ & $20,000.00$ & $\begin{array}{l}\text { Jembo Kabel NYYHY } \\
41,5 \mathrm{~mm} 2450 / 750 \mathrm{~V}\end{array}$ & 300 & $6,000,000.00$ \\
\hline 14 & Holder Fuse & $10,000.00$ & $\begin{array}{l}\text { Phoenix Contact UK 5-HESI; } \\
\text { IEO 60947-7-3; 800V 4mm2; } \\
\text { 6.3A }\end{array}$ & 7 & $70,000.00$ \\
\hline 15 & Terminal & $5,000.00$ & $\begin{array}{l}\text { Phoenix Contact Typ UK } 3 \mathrm{~N} ; \\
\text { IEC 60947-7-1; 600V 2.5mm2 }\end{array}$ & 50 & $250,000.00$ \\
\hline 16 & Glass Fuse & $5,000.00$ & $520 \mathrm{~mm} 0.5$ A $220 \mathrm{VAC}$ & 7 & $35,000.00$ \\
\hline 17 & Kable Tray & $34,000.00$ & Cable Tray $4445500 \mathrm{~mm}$ & 1 & $34,000.00$ \\
\hline 18 & $\begin{array}{c}\text { End } \\
\text { Terminal }\end{array}$ & $5,000.00$ & Phoenix Contact Typ Clipfix 35 & 6 & $30,000.00$ \\
\hline 19 & Relay & $20,000.00$ & OMRON MY4N & 2 & $40,000.00$ \\
\hline 20 & Socket Relay & $8,800.00$ & EWIG, DYF14A & 2 & $17,600.00$ \\
\hline 21 & Din Rail & $15,000.00$ & Alumunium, for terminal block & 1 & $15,000.00$ \\
\hline \multicolumn{5}{|c|}{ Biaya Total } & $89,234,080.00$ \\
\hline
\end{tabular}




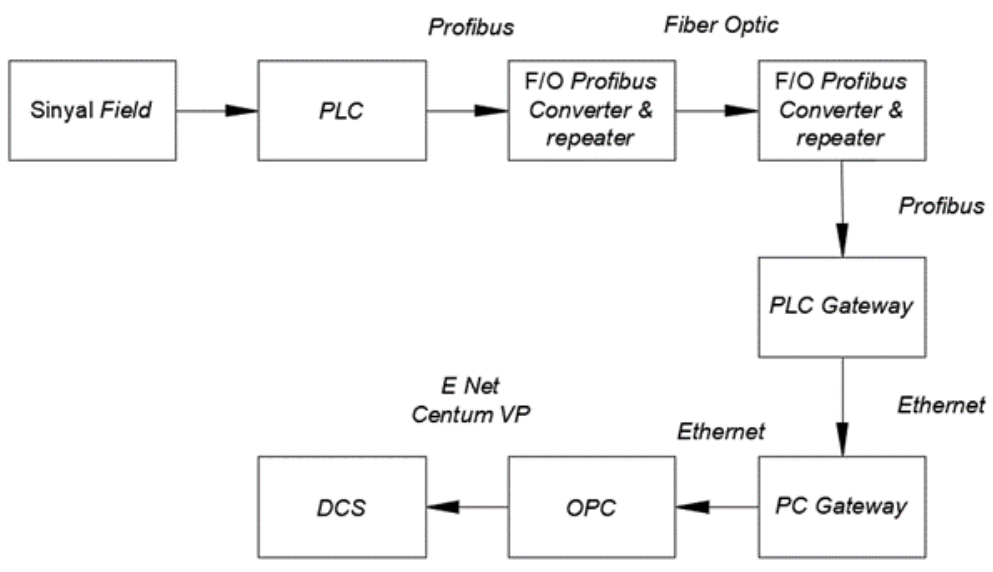

Gambar 4. Blok diagram PLC Grup Bag Filter 563-BF1 [3, 11]

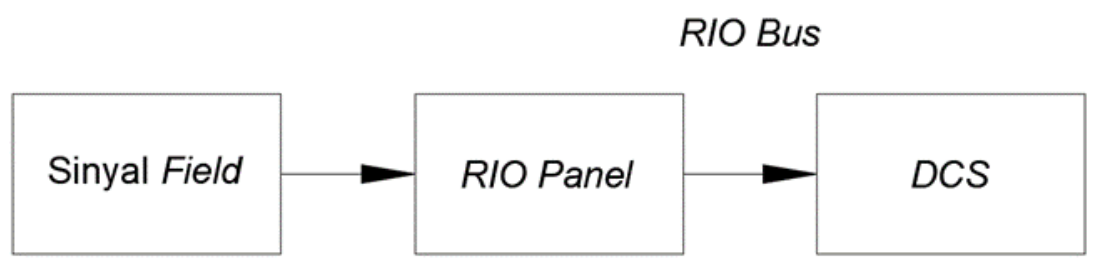

Gambar 5. Blok diagram DCS Grup Bag Filter 563-BF1 [3, 10]

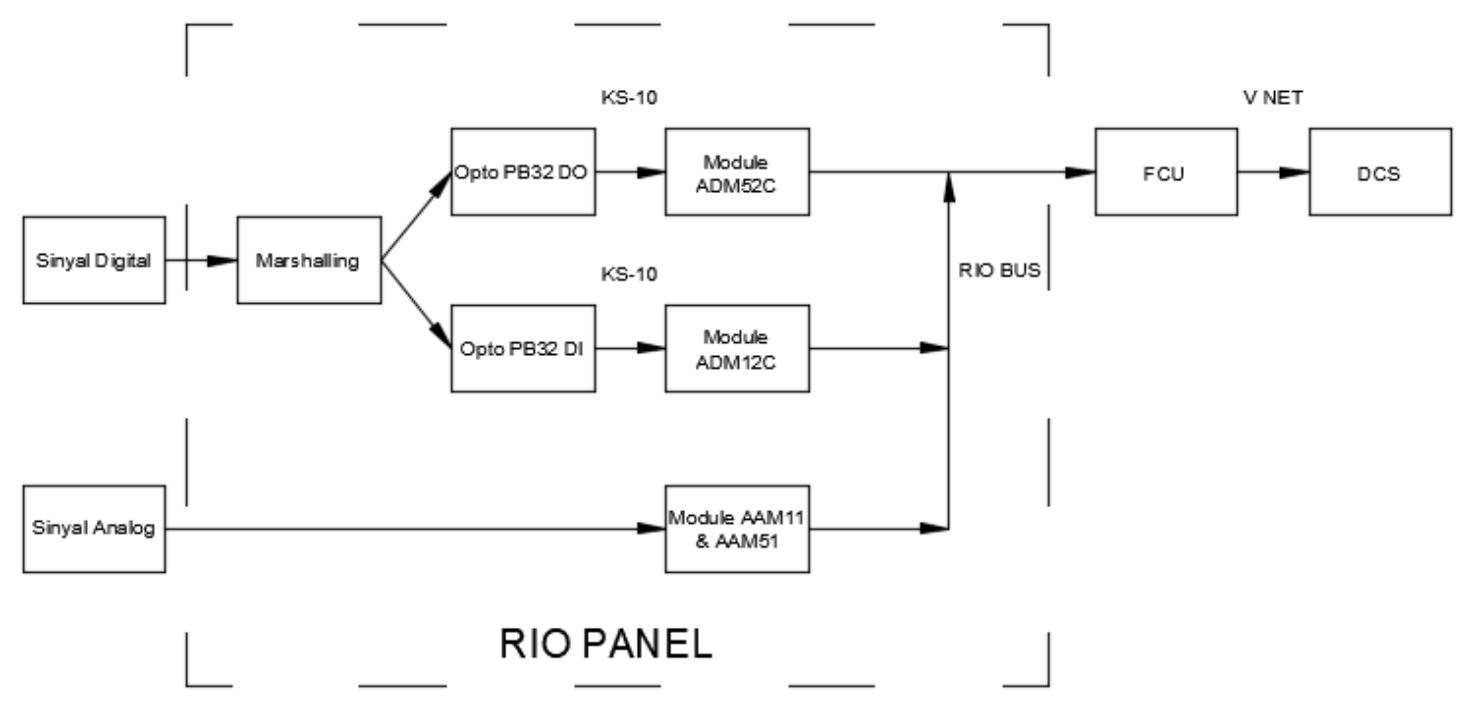

Gambar 6. Blok diagram komponen RIO panel [9] 
Jefri Gunawan, Fatahula dan Juhartono, Perubahan Sistem Kontrol...

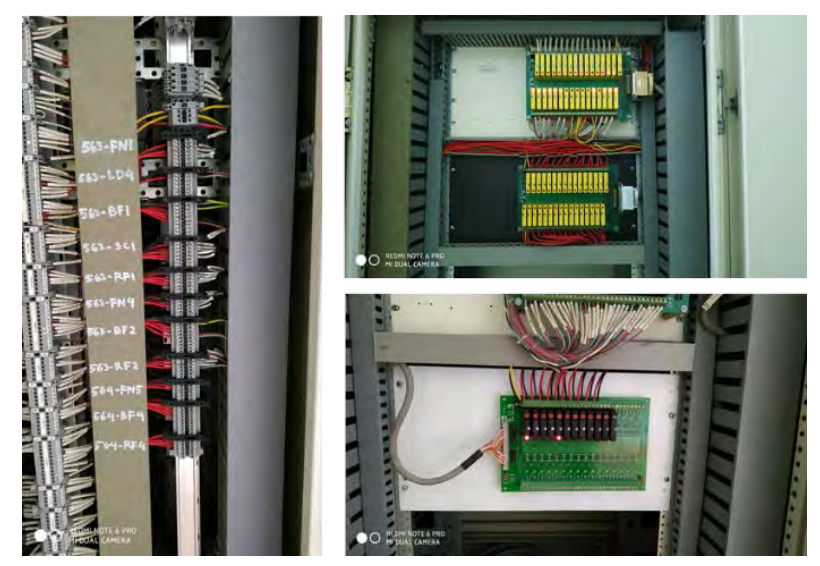

Gambar 7. Komponen RIO panel 